\title{
STUDY OF MORTALITY AND MORBIDITY OF PATIENTS OPERATED IN EMERGENCY FOR ILEAL PERFORATION PERITONITIS IN CENTRAL INDIA
}

\author{
Lal Mani Singh ${ }^{1}$, Ashok Nayak ${ }^{2}$ \\ ${ }^{1}$ Assistant Professor, Department of General Surgery, S. S. Medical College, Rewa. \\ ${ }^{2}$ Assistant Professor, (Neuro) Department of General Surgery, S. S. Medical College, Rewa.
}

\section{ABSTRACT}

Ileal perforation peritonitis is a common surgical emergency in the Indian subcontinent and in tropical countries. It is reported to constitute the fifth common cause of abdominal emergencies due to high incidence of enteric fever and tuberculosis in these regions.

\section{METHODS}

This study included 94 patients diagnosed with ileal perforation, admitted and treated in the Department of General Surgery from February 2011 to January 2012 in an Educational Institute of Central India.

\section{RESULT}

Out of the 94 patients studied, 72 (76.59\%) were males and 22 (23.4\%) were females; 8 patients had hypertension, 6 patients had diabetes and 8 patients both HT and DM; 48 patients were diagnosed to have typhoid fever and received antibiotics prior to hospitalization for perforation; 7 patients were taking ATT from DOT'S centre. All the 11 patients who died had symptoms for more than 24 hours. Seven of the 83 survivors had symptoms for more than five days. The surgical intervention was initiated within the first 24 hours of admission in 68 (72.34\%) of the patients. The overall mortality rate was $11.7 \%$ (11 patients).

\section{CONCLUSION}

Early recognition, timely surgical intervention, appropriate antibiotics and surgical technique, pre-operative, post and perioperative care play a key role in reducing mortality in ileal perforation.

\section{KEYWORDS}

Ileal Perforation, Mortality, Morbidity.

HOW TO CITE THIS ARTICLE: Singh LM, Nayak A. Study of mortality and morbidity of patients operated in emergency for ileal perforation peritonitis in Central India. J. Evolution Med. Dent. Sci. 2016;5(45):2809-2812, DOI: 10.14260/jemds/2016/656

\section{INTRODUCTION}

Acute generalized peritonitis from ileal perforation is a potentially life-threatening condition. It is the most important surgical complication of typhoid enteritis with significant morbidity and mortality and is very common in the IndoPakistan sub-continent. The mortality ranges between 9 and $43 \%$ with many of the survivors having severe wound infection and a history of long hospital stay.[1] Many factors such as late presentation, inadequate pre-operative resuscitation, delayed operation, the number of perforations and the extent of faecal peritonitis have been found to have a significant effect on the prognosis.

\section{MATERIAL AND METHODS}

This study included 94 patients diagnosed with ileal perforation, admitted and treated in the Department of General Surgery from February 2011 to January 2012 in an Educational Institute of Central India. A thorough history was taken and detailed examination done as per proforma. The cases were evaluated with regard to age, gender and clinical features, investigations, and intra-operative findings, type

Financial or Other, Competing Interest: None.

Submission 08-04-2016, Peer Review 12-05-2016,

Acceptance 19-05-2016, Published 06-06-2016.

Corresponding Author:

Dr. Lal Mani Singh,

Department of General Surgery,

Sanjay Gandhi Memorial Hospital,

Rewa-486001,

Madhya Pradesh.

E-mail: lalmnsingh@gmail.com

DOI: $10.14260 /$ jemds/2016/656 of surgery, morbidity and mortality. All patients initially presented to the emergency department, because of acute abdomen. They were subjected to erect X-ray abdomen, chest $\mathrm{X}$-ray PA view, complete blood count, urine analysis, renal function test, serum electrolytes. All patients underwent surgery after pre-operative resuscitation; the patients were subjected to exploratory laparotomy under General Anaesthesia. Operative findings were recorded and edge biopsy at the perforation site or the resected specimen was sent for histopathological examination. The type of surgical procedure was decided on basis of operative findings. Delay in operation was the time period calculated from the time of onset of severe symptomatology like exacerbation of abdominal pain, distention and vomiting. Postoperatively, the patients were followed up for any complication like faecal fistula.

\section{RESULT}

Out of the 94 patients studied, $72(76.59 \%)$ were males and 22 $(23.4 \%)$ were females. The youngest was 16 years old and oldest was 85 years. Type of operative procedure and mortality are depicted in (Table 1). All patients were septic on admission.

The most common presentation was pain abdomen seen in 85 patients with mean duration of 3.49 days. Fifty two patients had history of pain abdomen less than 4 days. Bowel disturbances were present in 92 (97.87\%) patients, out of whom 72 patients had constipation, 12 patients had loose stools and 8 patients had vomiting. Comorbidities were also present in 22 patients; 8 patients had hypertension, 6 patients had diabetes and 8 patients both HT and DM; 48 patients were 
diagnosed to have typhoid fever and received antibiotics prior to hospitalization for perforation; 7 patients were taking ATT from DOT centre. On examination 78 (82.97\%) patients had diffuse peritonitis, $14(14.89 \%)$ patients had localized peritonitis, whereas $2(2.12 \%)$ patients had no peritonitis.

All the 11 patients who died had symptoms for more than 24 hours; 7 of the 83 survivors had symptoms for more than 5 days. The surgical intervention was initiated within the first 24 hours of admission in $68(72.34 \%)$ of the patients. The overall mortality rate was $11.7 \%$ (11 patients) (Table 1 ).

All the patients underwent midline laparotomy. Single perforation of ileum was noted in $81(86.17 \%)$ patients, 4 $(4.25 \%)$ patients had 2 perforations and more than 2 perforations were present in 9 (9.57\%). Size of perforation varied from $0.5 \mathrm{~cm}$ to $3 \mathrm{~cm}$. Location of perforation was within $5 \mathrm{~cm}$ from ileocaecal junction in $22(23.40 \%)$ patients, $20-40$ $\mathrm{cm}$ from ileocaecal junction in $60(63.82 \%)$ patients and 12 (12.76\%) patients had perforation beyond $40 \mathrm{~cm}$ from ileocaecal junction. Peritoneal collection was purulent in 58 (61.70\%) patients, feculent in $29(30.85 \%)$ patients and bile stained in 7 (7.45\%) patients.

The choice of surgical procedure depended on patient's general condition, peritoneal contamination, inflamed bowel, location and number of perforation. Primary closure of perforation without ileostomy was done in 39 (41.50\%), that patients who had single perforation with good GC; 42 $(44.68 \%)$ patients were selected for primary repair with ileostomy, these patients had bad GC and other parameters with extensive bowel inflammation and feculent collection; 9 $(9.57 \%)$ underwent resection anastomosis and ileostomy who had multiple perforation with faeco-purulent collection and bad GC. Two was operated outside and presented with faecal fistula and explored them and resection anastomosis with proximal ileostomy was done.

Intensive Care Unit (ICU) admission was required in $46.4 \%$ of the patients. All the non-survivors (11 patients) were admitted to the ICU and had to be ventilated postoperatively.

Post-operative recovery was uneventful in 64 (68.08\%), thirty (31.91\%) patients had complications as shown in (Table 4). Two patients developed intra-abdominal collection and one patient developed enterocutaneous fistula, both complications were managed conservatively. Culture revealed E. coli as the main organism in $58(61.70 \%)$ patients (Table-5), Widal test was positive in 61 (64.89\%) patients.

Sixty two $(65.95 \%)$ patients were discharged within 10 days. Thirty one $(32.97 \%)$ patients were discharged between 10 to 25 days and only $1(1.06 \%)$ patient stayed in the hospital for more than a month.

\begin{tabular}{|c|c|c|c|c|}
\hline $\begin{array}{c}\text { Sl. } \\
\text { No. }\end{array}$ & Procedure & $\begin{array}{c}\text { No. of } \\
\text { Cases }\end{array}$ & Mortality & $\%$ \\
\hline 1 & $\begin{array}{c}\text { Primary closure } \\
\text { with ileostomy }\end{array}$ & 44 & 06 & 6.38 \\
\hline 2 & $\begin{array}{c}\text { Primary closure } \\
\text { without ileostomy }\end{array}$ & 39 & 02 & 2.13 \\
\hline 3 & $\begin{array}{c}\text { Re-exploration \& } \\
\text { ileostomy }\end{array}$ & 02 & - & - \\
\hline 4 & $\begin{array}{c}\text { Resection and } \\
\text { anastomosis }\end{array}$ & 09 & 03 & 3.19 \\
\hline \multicolumn{5}{|c|}{ Total Table 1: Mortality Rate among Various Operative } \\
Processors
\end{tabular}

\begin{tabular}{|c|c|c|c|c|c|c|}
\hline \multirow[b]{2}{*}{ POI } & \multicolumn{4}{|c|}{ Type of Procedure } & \multirow[b]{2}{*}{ Mortality } & \multirow[b]{2}{*}{$\%$} \\
\hline & $\begin{array}{c}\text { Primary Closure } \\
\text { with Ileostomy }\end{array}$ & $\begin{array}{c}\text { Primary Closure } \\
\text { without Ileostomy }\end{array}$ & $\begin{array}{l}\text { Resection \& end-to- } \\
\text { end Anastomosis }\end{array}$ & $\begin{array}{c}\text { Resection } \\
\text { with ITA }\end{array}$ & & \\
\hline$<48$ hrs. $(\mathrm{n}=44)$ & 17 & 26 & 01 & 00 & 02 & 4.54 \\
\hline $\begin{array}{c}\text { 48-120 hrs. } \\
(\mathrm{n}=38)\end{array}$ & 19 & 10 & 8 & 01 & 04 & 10.52 \\
\hline $\begin{array}{c}>120 \mathrm{hrs} . \\
(\mathrm{n}=12)\end{array}$ & 08 & 03 & - & 01 & 05 & 41.67 \\
\hline
\end{tabular}

\begin{tabular}{|c|c|c|c|}
\hline \multirow{2}{*}{\multicolumn{2}{|c|}{ Parameter }} & \multicolumn{2}{|c|}{ Mortality } \\
\hline & & No. & $\%$ \\
\hline \multirow{2}{*}{$\mathrm{Hb}$} & $<10$ gm $\%$ & 7 & 7.45 \\
\hline & $>10 \mathrm{gm} \%$ & 4 & 4.25 \\
\hline \multirow{2}{*}{ No. of perforation } & Single & 3 & 3.19 \\
\hline & Multiple & 8 & 8.51 \\
\hline \multirow{2}{*}{ Duration after operation } & $<48$ hrs. & 2 & 2.13 \\
\hline & $>48$ hrs. & 9 & 9.57 \\
\hline
\end{tabular}

\begin{tabular}{|c|c|c|}
\hline Complications & $\begin{array}{c}\text { Number of } \\
\text { Patients (n=94) }\end{array}$ & \% \\
\hline Nil & 64 & 68.08 \\
\hline Present & 30 & 31.91 \\
\hline • Surgical site infections & 16 & 17.02 \\
\hline • Chest complication & 11 & 11.70 \\
\hline • Enterocutaneous fistula & 1 & 1.06 \\
\hline - Intra-abdominal abscess & 2 & 2.12 \\
\hline \multicolumn{2}{|c|}{ Table 4: Distribution of Post-operative } \\
Complications in Patients Studied \\
\hline
\end{tabular}

\begin{tabular}{|l|c|c|}
\hline \multicolumn{1}{|c|}{ C/S } & Number of Patients & \% \\
\hline 1. E. coli & 58 & 61.70 \\
\hline 2. Enterococcus & 21 & 22.34 \\
\hline 3. ESBL (E-coli) & 5 & 5.31 \\
\hline 4. Klebsiella & 7 & 7.44 \\
\hline 5. None & 3 & 3.19 \\
\hline \multicolumn{2}{|c|}{$\mathbf{9 4}$} \\
\hline \multicolumn{2}{|c|}{ Table 5: Distribution of Organisms Isolated on Culture of Peritoneal Collection } \\
\hline
\end{tabular}




\begin{tabular}{|c|c|c|c|c|}
\hline Sl. No. & Study [References] & Year & No. of Patients Studied & Number of Mortality (\%) \\
\hline & Our study & $2011-2012$ & 94 & $11(11.7)$ \\
\hline 1 & Kouame et al[29] & $1995-1998$ & 64 & $22(34 \%)$ \\
\hline 2 & Agbakwuru et al[27] & $1988-2001$ & 105 & $6(13.36) \%$ \\
\hline 3 & Ansari et al[25] & $2003-2008$ & 44 & $18(16 \%)$ \\
\hline 4 & Saxe et al[29] & 2003 & 112 & $1(4.5 \%)$ \\
\hline 5 & Sumer et al[3] Table 6: Comparison of Mortality in Different Studies \\
\hline \multicolumn{4}{r}{} \\
\hline
\end{tabular}

\section{DISCUSSION}

Perforation of the ileum is seen frequently in India with a preponderance among males, similar to observations of other previous authors.[1] which is similar to reported by Wani et al $3: 1,[2] 4: 1$ reported by Adesunkanmi et al[3] and Talwar et al[4] 6.4:1 reported by Beniwal et al[5] and 6.5:1 reported by Prasad et al.[6] One possible reason for this may be due to the fact that enteric fever is more common in males, possibly because of more exposure to infection. The age range and mean age of our patients were also similar to previous findings of other authors.[7,8,9-11] Although the prognosis of ileal perforation remains poor according to most reported series in similar environments, the overall mortality (Table 1) in our patients was $11(11.7 \%)$ we found, as was the experience of most other authors the overwhelming incidence of wound infection and other wound related complications (Dehiscence) in the survivors. Most common complication in this study was surgical site infection (Table 4), which is similar to a study by Ansari et al.[12] Enterocutaneous fistula was found in 1 (2.5\%) patient, similar to study by Sumer et al.[13] This was managed conservatively. Fistula closed spontaneously. In a study by Ansari et al, fistula was found in $13.4 \%$ patients.[12] Major cause of post-operative morbidity in perforation peritonitis according to Jhobta et al, is respiratory complication.[14] In this study, 6 patients (15\%) developed respiratory complication.

Symptoms and signs are not different from those in other geographical areas with a mean duration of symptoms (Onset of abdominal pain) before presentation being 3-5 days and $40 \%$ of the patients presenting within 3 days of onset of symptoms with fever, headache and generalized abdominal pain being the major complaints. These findings are in agreement with previous reports of early perforation being very common in West Africa.[14,15,16] Late presentation and delay in operation were associated with high mortality and a high incidence of faecal fistula, whereas early presentation was associated with the development of other complications, although mortality was far lower in the latter group.[14,17] The need for adequate resuscitation resulted in a delay before operation in some of our patients who had presented in a poor state, which was also found to affect the outcome adversely.[15,18,19,20] We have not found any differences in survival between male and female patients; neither have we found the patient's ages to be an important prognostic factor. Our findings are in agreement with previous studies. The presence of single perforations and moderate peritoneal contamination favoured the development of complications such as wound infection, wound dehiscence and residual intraabdominal abscess, in those patients who survived to develop these complications. We, however, found the presence of multiple perforations to be associated with a very poor prognosis with a mortality of $8.51 \%$ Table 3 , which is very low than previous studies.[14,15,17,18,19] Adequate resuscitation, correction of electrolyte disturbance, appropriate antibiotic therapy and surgery have proven to be essential. Not only has surgical intervention sharply reduced mortality from 70 $100 \%$ to about $30 \%$, 3-5 but also early surgical intervention has further improved the prognosis as validated by the present study and also documented the work of various other authors. $[17,18,19,20,21]$

Excision of the edge of the ileal perforation and simple transverse closure, either in a single layer or in two layers, ileostomy have been the most widely practiced procedure. Many workers.[21,22,23,24,] claimed that segmental resection of the involved bowel may be necessary in the presence of multiple perforations and a severely diseased terminal ileum. Recently, some workers have recommended segmental resection and primary end-to-end anastomosis of the diseased perforated ileum.[25] Other workers advocated closure of the perforation with end-to-side ileo-transverse bypass; this diverts the involved bowel out of the main intestinal stream.[26] Depending on circumstances, we closed the abdominal wall with tension sutures. The use of a tension closure, so as to prevent possible wound dehiscence has been demonstrated by various other workers.[27,28]

\section{CONCLUSION}

Ileal perforation is a major surgical health problem in India, particularly in those where standard of living is low which leads to unhygienic environment. Early recognition, timely surgical intervention, appropriate antibiotics and surgical technique, pre-operative, post- and peri-operative care play a key role in reducing mortality in ileal perforation. However, this is a retrospective observational study. This has all the limitations of retrospective study to come to any opinion. This warrants a prospective study to come to a definitive conclusion.

\section{REFERENCES}

1. Sushil Mittal, Harnam Singh, Anand Munghate, et al. A comparative study between the outcome of primary repair versus loop ileostomy in ileal perforation. Surgery Research and Practice Article ID 729018, 2014;p 4.

2. Wani RA, Parray FQ, Bhat NA, et al. Nontraumatic terminal ileal perforation. World J Emerg Surg 2006;1:7.

3. Adesunkanmi RK, Badmus TA, Fadiora FO, et al. Generalized peritonitis secondary to typhoid ileal perforation: assessment of severity using modified APACHE II score. Indian Journal of Surgery 2005;67(1):29-33.

4. Talwar S, Sharma RK, Mittal DK, et al. Typhoid enteric perforation. Australian and New Zealand Journal of Surgery 1997;67(6):351-3.

5. Beniwal U, Jindal D, Sharma J, et al. Comparative study of operative procedures in typhoid perforation. Indian Journal of Surgery 2003;65(2):172-7. 
6. Prasad PB, Choudhury DK, Prakash O. Typhoid perforation treated by closure and proximal side-to-side ileo-transverse colostomy. Journal of the Indian Medical Association 1975;65(11):297-9.

7. Hemkant Verma, Siddharth Pandey, Kapil Dev Sheoran, et al. Surgical audit of patients with ileal perforations requiring ileostomy in a tertiary care hospital in India. Surgery Research and Practice Article ID-351548, 2015;p 4. http://dx.doi.org/10.1155/2015/351548.

8. Jhobta RS, Attri AK, Kaushik R, et al. Spectrum of perforation peritonitis in India-review of 504 consecutive cases. World Journal of Emergency Surgery 2006;1:26.

9. Patil V, Vijayakumar A, Ajitha MB, et al. Comparison between tube ileostomy and loop ileostomy as a diversion procedure. ISRN Surgery Article ID-547523, 2012;p 5.

10. Ali MZ, Munir K, Zaffar A, et al. Surgical audit of emergency ileostomies. Journal of Rawalpindi Medical College 2012;16(1):45-7.

11. Batra P, Gupta D, Rao S, et al. Spectrum of gastrointestinal perforation peritonitis in rural central India. Journal of Mahatma Gandhi Institute of Medical Sciences 2013;18(1):44-8.

12. Abdul Ghaffar Ansari, Syed Qaiser Hussain Naqvi, Ali Akbar Ghumro, et al. Management of typhoid ileal perforations: a surgical experience of 44 cases. Gomal Journal of Medical Sciences 2009;7(1):27-30.

13. Sumer A, Kemik O, Dulger AC, et al. Outcome of surgical treatment of intestinal perforation in typhoid fever. World journal of Gastroenterol 2010;16(33):41648.

14. Van Der Werf TS, Cameron ES. Typhoid perforation of the ileum: a review of 59 cases seen at agogo hospital, ghana between 1982 and 1987. Trop Geogr Med 1990;42(4):330-6.
15. Archampong EQ. Typhoid Ileal perforation: why such mortality. Br J Surg 1976;63(4):317-21.

16. Adeloye A. Typhoid fever. In: Adeloye A, ed. Davey's Companion to Surgery in Africa. Edin burgh: Churchill Livingstone 1987; $2^{\text {nd }}$ ed:309-16.

17. Butler $\mathrm{T}$, Knight J, Nath $\mathrm{SK}$, et al. Typhoid fever complicated by intestinal perforation: a persisting fatal outcome requiring surgical management. Rev Infect Dis 1985;7(2):244-56.

18. Gibney El. Typhoid enteric perforation in Rural Ghana. J Coll Phys Surg 1988;17:105.

19. Meier DE, Imediegwu O0, Tarpley JL. Perforated typhoid enteristis: operative experience with 108 Cases. Am J Surg 1989;157(4):423-7.

20. Keenan JP, Hadley GP. The surgical management of typhoid perforation in children. $\mathrm{Br} J$ Surg 1984;71(12):928-9.

21. Kim JP, Oh SK, Jarrett F. Management of ileal perforation due to typho id fever. Ann Surg 1975;181(1):88-91.

22. Khana AK, Misra MK. Typhoid perforation of the gut. Postgrad med J 1984;60(706):523-5.

23. Eustach JM, Kreis DJ. Typhoid perforation of the intestine. Arch Surg 1983;118(11):1269-71.

24. Adesunkanmi ARK, Ajao OG. Typhoid ileal perforation: the value of delayed primary closure of abdominal wound. Afr J Med Medic Sci 1996;25:31-5.

25. Kaul BK. Operative management of typho id perforation in children. Int Surg 1975;60(8):407-10.

26. Eggleston FC, Santoshi B, Singh CM. Typhoid perforation of bowel experiences in 78 cases. Ann Surg 1979;190(1):31-5.

27. Olurin FO, Ajaji 00, Bohrer SP. Typhoid perforation. J Coll Surg Edinb 1972;17:253-63.

28. Ajao OG. Typhoid perforation: factors affecting mortality and morbidity. Int Surg 1982;67:317-9. 